This is a pre-print version of: Howey, D.A., et al., Comparative measurements of the energy consumption of 51 electric, hybrid and internal combustion engine vehicles, Transportation Research D (2011), DOI 10.1016/j.trd.2011.04.001

\title{
Comparative measurements of the energy consumption of 51 electric, hybrid and internal combustion engine vehicles
}

\author{
D.A. Howey ${ }^{1 *}$, R.M. Martinez-Botas ${ }^{1}$, B. Cussons ${ }^{2}$, L. Lytton ${ }^{3}$ \\ 1. Mechanical Engineering Department, Imperial College, Exhibition Road, South Kensington, \\ London SW7 2AZ, UK, email d.howey@imperial.ac.uk, tel. +44 (0) 207594 5271, fax. +44 (0)20 78238845 \\ 2. Royal Automobile Club, 89-91 Pall Mall, London SW1Y 5HS, UK, email ben@cussons.org.uk \\ 3. RAC Foundation, 89-91 Pall Mall, London SW1Y 5HS, UK, email luca.lytton@racfoundation.org
}

\begin{abstract}
This paper presents the measured energy consumption results of a range of efficient vehicles over a 57 mile urban / extra-urban route. The results show that on average the electric vehicles used the least amount of energy (average $0.62 \mathrm{MJ} / \mathrm{km}$ ), followed by the hybrid vehicles (average 1.14 $\mathrm{MJ} / \mathrm{km}$ ), and the internal combustion engine vehicles (average $1.68 \mathrm{MJ} / \mathrm{km}$ ). The hydrogen fuel cell vehicle used $1.2 \mathrm{MJ} / \mathrm{km}$. An estimate of $\mathrm{CO}_{2}$ emissions was also made and it was found that hybrids gave the lowest $\mathrm{CO}_{2}$ emissions, with around half of the vehicles emitting less than 70 $\mathrm{gCO}_{2} / \mathrm{km}$. The most efficient diesel combustion engine vehicles emitted about $80 \mathrm{gCO}_{2} / \mathrm{km}$ but the majority exceeded $110 \mathrm{gCO}_{2} / \mathrm{km}$. The majority of electric vehicles emitted $70-110 \mathrm{gCO}_{2} / \mathrm{km}$ assuming a United Kingdom grid average emissions factor of $542 \mathrm{gCO}_{2} / \mathrm{kWh}$.
\end{abstract}

Keywords: vehicle energy consumption, vehicle fuel efficiency, electric vehicle, hybrid vehicle, vehicle $\mathrm{CO} 2$ emissions

\section{Introduction}

In 2010, Britain's Royal Automobile Club (RAC) organised the first Brighton to London Future Car Challenge (BLFCC) in order to promote and demonstrate new cleaner vehicle technologies. The event provided an opportunity to measure the comparative energy consumption of a range of prototype, pre-production and production passenger vehicles on a like-for-like basis. The objective of the challenge was to drive the 57 mile route - a mix of urban and extra-urban driving - using as little energy as possible. It was left to each driver to decide the best 'eco-driving' technique, although a maximum and minimum time for the route was specified. Vehicles were categorised both in terms of powertrain type and size as shown in Table 1:

Table 1: Vehicle types and sizes

\begin{tabular}{ll} 
Powertrain types & Vehicle sizes/types \\
\hline Internal Combustion Engine (ICE) & Small passenger vehicle (small) \\
Electric Vehicle (EV) & Regular passenger vehicle (regular) \\
Hybrid Electric Vehicle (HEV) & Sports vehicle (sports) \\
Plug-in Hybrid Electric Vehicle (PHEV) & Multi-purpose passenger vehicle (MPV) \\
Hydrogen Fuel-cell Electric Vehicle (HFEV) & Light commercial vehicle (LCV) \\
Extended-Range Electric Vehicle (E-REV) &
\end{tabular}

\section{Methodology}

A unified methodology was required for energy measurement across the wide range of competing vehicles. Each vehicle was considered to be an independent thermodynamic system with the system boundary being the vehicle envelope itself. This means that the actual details of the powertrain topology and types of energy storage were abstracted away from the measurement method. Upstream inefficiencies beyond the petrol pump or power station were not considered. The ideal method for energy measurement is to ensure that the vehicle is filled up to $100 \%$ capacity with energy (from one or multiple sources as necessary to the powertrain type) in a controlled fashion at the start, then refilled back to $100 \%$ at the finish. The amount of energy required to refill at the finish should then equal the energy used during the run.

\footnotetext{
* Corresponding author
} 
This is a pre-print version of: Howey, D.A., et al., Comparative measurements of the energy consumption of 51 electric, hybrid and internal combustion engine vehicles, Transportation Research D (2011), DOI 10.1016/j.trd.2011.04.001

This approach can be applied directly to petrol and diesel fuelled ICE vehicles as long as it is possible to measure the fuel level and filling amount accurately. At the event start, each vehicle had its fuel tank topped up to maximum on level ground and then sealed. At the finish, the tanks were topped up using the same technique and the amount of fuel required was measured in litres. The calorific values of the fuels were: Petrol $30.8 \mathrm{MJ} /$ litre, Diesel $37.6 \mathrm{MJ} /$ litre. It was estimated that the uncertainty in fuel measurement at start and finish was \pm 0.1 litres each, giving an overall uncertainty of around \pm 0.14 litres (combining in quadrature) i.e. $\pm 4.4 \mathrm{MJ}$ for petrol vehicles and $\pm 5.3 \mathrm{MJ}$ for diesel vehicles for the total trip; this was normalised to give figures per $\mathrm{km}$.

There are unfortunately two significant challenges in applying this measurement approach directly to electric and hybrid vehicles:

1. It can take a substantial amount of time to charge to $100 \%$ at the start and finish. For example, a $24 \mathrm{kWh}$ battery pack may take around 8 hours to fully charge from a single phase UK mains electricity socket supplying $3 \mathrm{~kW}$ maximum. Therefore a different strategy was required for EVs, as discussed in section 2.1.

2. Both hybrids and PHEVs/E-REVs typically contain a sizeable battery in addition to the fuel tank. It was difficult or impossible to access and measure directly the state of charge (SOC) of the battery at the start and finish of the challenge. However, non plug-in hybrids operate in 'charge sustaining' mode, where the battery is kept within a narrow SOC range (for example $60-80 \%$ SOC) at all times. Therefore any differences in battery SOC between start and finish were ignored, i.e. hybrids were treated in the same way as conventional ICE vehicles and the same fuel measurement technique was applied.

In the case of PHEVs/E-REVs, which may operate in charge sustaining or charge depleting mode, a separate measurement of the electrical energy should be made and this was not possible. However, only two vehicles of this type entered the challenge. For the purpose of this paper their results have been omitted.

The calorific value of hydrogen is $120 \mathrm{MJ} / \mathrm{kg}$. The only practical way to measure the stored hydrogen at start and finish was to use the vehicle's dashboard display. The uncertainty in hydrogen measurement was estimated at $\pm 0.005 \mathrm{~kg}$ i.e. $\pm 0.6 \mathrm{MJ}$.

\subsection{Electrical energy measurement technique}

The electric vehicles were fitted with a data logger which recorded both current and voltage on the high voltage (HV) DC bus between the battery pack and motor controller(s). A hall effect current sensor was used with a range of $\pm 750 \mathrm{~A}$ feeding a 10-bit analog-to-digital converter. The high voltage measurement was made by connecting a high value resistor across the bus to generate a small leakage current which was then measured using another current transducer. The range was 0-450 V, also feeding a 10-bit ADC. Both of the transducers used for current and voltage measurement were temperature compensated and individually calibrated before installation.

The disadvantage of using this method to record energy consumption is that the measurement has to be made between the battery and load (Figure 1), which means that the system boundary as previously defined is no longer respected. To get an accurate energy consumption estimate, some details about the upstream component losses must be assumed.

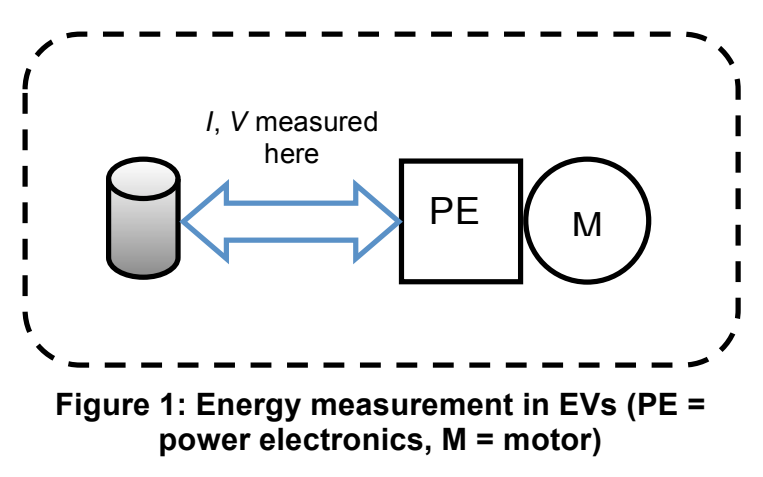


This is a pre-print version of: Howey, D.A., et al., Comparative measurements of the energy consumption of 51 electric, hybrid and internal combustion engine vehicles, Transportation Research D (2011), DOI 10.1016/j.trd.2011.04.001

The two components upstream of the measurement point are the battery pack and battery charger. At the modest charging levels being considered here ( $3 \mathrm{~kW}$ from a single phase supply) a battery charger operates with an efficiency of 90-95\% (AC Propulsion 2011, BRUSA 2011). Therefore a battery charger efficiency of $92 \pm 2 \%$ was assumed for all EVs.

Although an EV battery pack consists of many individual cells, according to Thevenin's theorem it may be represented by a single ideal voltage source $E$ with a series resistance $R$ representing the ohmic losses. The series resistance was not known for most of the EVs participating in the event. However, a measurement was made for one participating vehicle and it was found that $R=160$ $\mathrm{m} \Omega$. The power loss during discharging, which is dominated by ohmic losses, is given by $P_{\text {loss }}=$ $I^{2} R$. Using the logged data, shown in Figure 2, the averaged discharge loss $\left\langle P_{\text {loss }}\right\rangle=\langle 1\rangle^{2} R$ was found to be $48 \mathrm{~W}$, against an average discharge power $<\mid>\mathrm{V}$ of $4.6 \mathrm{~kW}$ during the journey. Therefore the mean discharging efficiency for this particular car on this particular journey is 4.6 / $(4.6+0.048)=99 \%$. The mean charging efficiency for kinetic energy recovered from braking was also found, and was also equal to $99 \%$. The power loss during overnight charging, prior to the event, assuming a $3 \mathrm{~kW}$ supply, is equal to approximately $10 \mathrm{~W}$. This makes negligible difference to the energy calculations and can be ignored.

Series resistance measurements of the other participating EVs were not available, and therefore it was assumed that all participating EVs had the same charge/ discharge efficiency of $99 \%$.
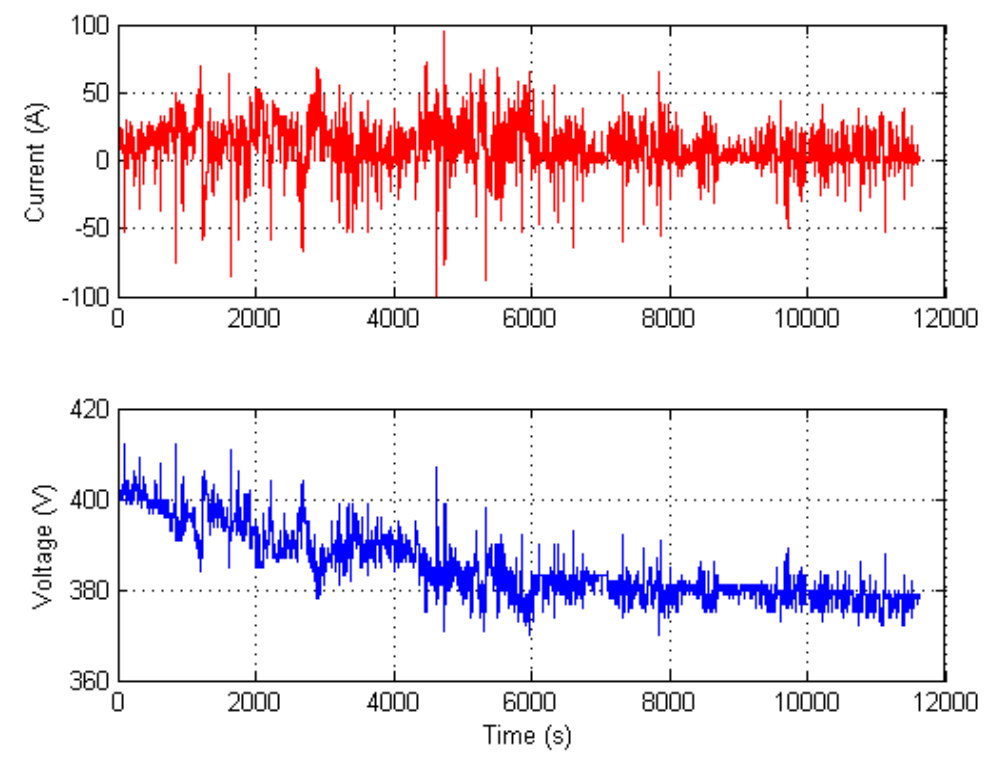

Figure 2: DC bus current and voltage recorded during the BLFCC event for one of the electric vehicles

In summary, the total energy consumption for the electric vehicles was calculated according to the formula:

$$
E=\frac{1}{\eta_{b c}}\left[\frac{1}{\eta_{d}} A-\frac{1}{\eta_{c}} B\right]
$$

where $A$ is the energy consumed during battery discharging, $B$ is the energy recovered during braking, $\eta_{c}=\eta_{d}=0.99$ the efficiency of charging/discharging the battery pack respectively, $\eta_{b c}=$ 0.92 is the efficiency of the AC/DC battery charger. This can therefore be simplified to:

$$
E=\frac{1}{0.92} \frac{1}{0.99}[A-B]=1.098[A-B]
$$

The net energy consumed is found by integrating the instantaneous power consumption.

\section{Results}

\subsection{Energy consumption}


This is a pre-print version of: Howey, D.A., et al., Comparative measurements of the energy consumption of 51 electric, hybrid and internal combustion engine vehicles, Transportation Research D (2011), DOI 10.1016/j.trd.2011.04.001

The measured energy consumption results are shown in Figure 4 in rank order from least to most, normalised to $\mathrm{MJ} / \mathrm{km}$ and also summarised in Table 2 along with petrol equivalent litres $/ 100 \mathrm{~km}$, mpg US and mpg Imperial.

Table 2: Summary of energy consumption results

\begin{tabular}{lllll} 
Vehicle type & $\begin{array}{l}\text { MJ/km } \\
\text { (average) }\end{array}$ & $\begin{array}{l}\text { litres/100km petrol } \\
\text { equivalent }\{1\}\end{array}$ & $\begin{array}{l}\text { mpg US petrol } \\
\text { equivalent }\{2\}\end{array}$ & $\begin{array}{l}\text { mpg Imperial petrol } \\
\text { equivalent }\{3\}\end{array}$ \\
\hline EV & $0.5-1(0.615)$ & $1.6-3.2(2.0)$ & $72-145(118)$ & $87-174(141)$ \\
\hline HEV & $0.7-2.1(1.14)$ & $2.3-6.8(3.7)$ & $34-103(64)$ & $41-124(76)$ \\
\hline ICE & $0.9-2.4(1.68)$ & $2.9-7.8(5.45)$ & $30-80(43)$ & $36-97(52)$ \\
\hline HFEV & 1.2 & 3.9 & 60 & 73 \\
\hline
\end{tabular}

$\{1\}$ The factor for conversion of $\mathrm{MJ} / \mathrm{km}$ to litres $/ 100 \mathrm{~km}$ petrol equivalent is 3.25

$\{2\}$ The factor for conversion of $\mathrm{MJ} / \mathrm{km}$ to US gallons/mile is $0.0138-\mathrm{mpg}$ is the reciprocal of this

$\{3\}$ The factor for conversion of $\mathrm{MJ} / \mathrm{km}$ to Imperial gallons $/ \mathrm{mile}$ is 0.0115

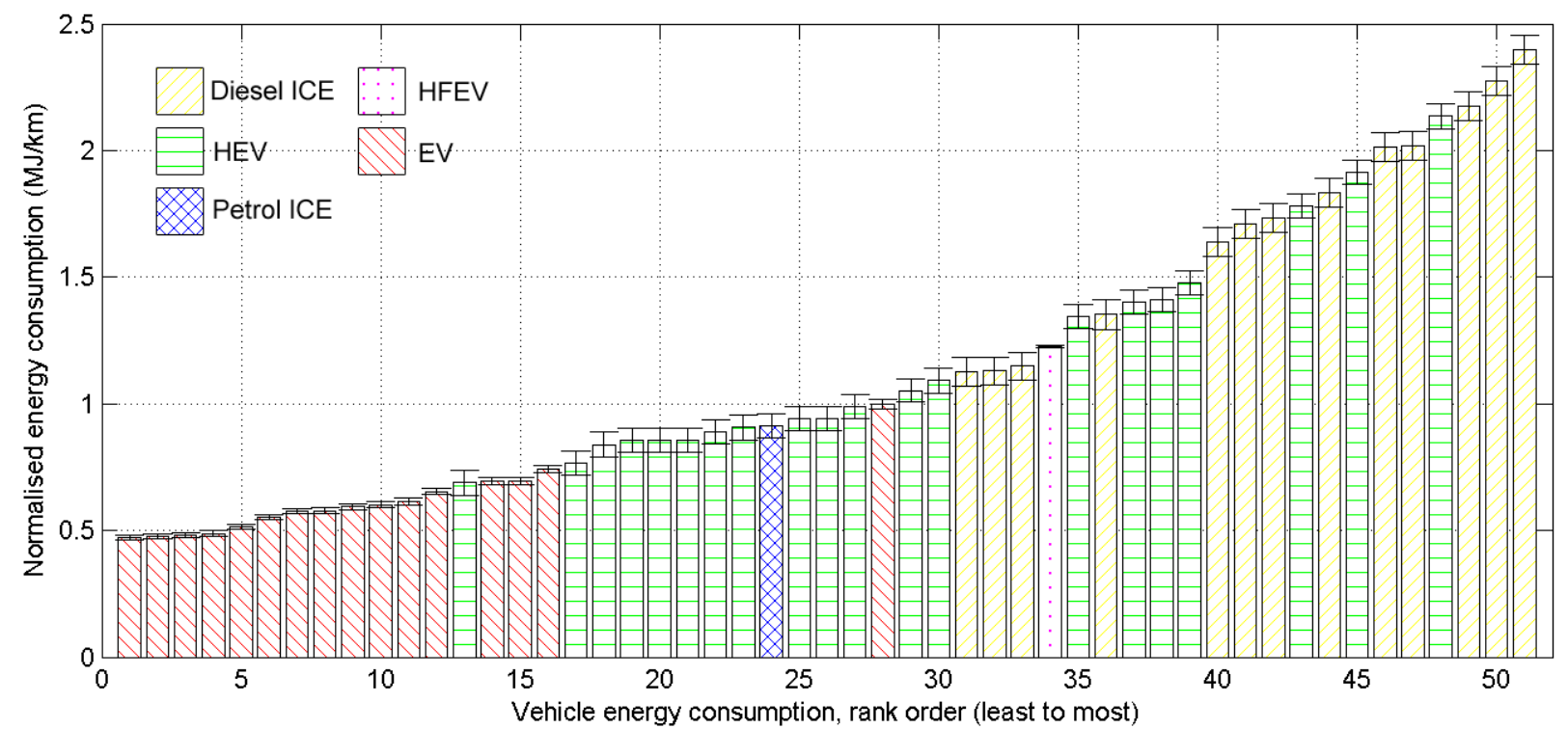

Figure 3: Fuel consumption results including uncertainty margins

\section{$3.2 \mathrm{CO}_{2}$ emissions}

An estimate of $\mathrm{CO}_{2}$ emissions for each vehicle was also made based on the emissions factors in Table 3. Figure 5 shows the resulting approximate equivalent $\mathrm{CO}_{2}$ emissions in rank order from least to most with the results summarised in Table 4.

Table 3: $\mathrm{CO}_{2}$ emissions conversion factors

\begin{tabular}{lll} 
& $\mathrm{CO}_{2}$ emissions $(\mathrm{g} / \mathrm{MJ})$ & Assumption \\
\hline Petrol & 74.7 & $\begin{array}{l}\text { Calorific value of } 30.8 \mathrm{MJ} / \text { litre and } \mathrm{CO}_{2} \\
\text { emissions 2.302 } \mathrm{kgCO} / \text { /itre (DEFRA, 2010) }\end{array}$ \\
\hline Diesel & 70.2 & $\begin{array}{l}\text { Calorific value of } 37.6 \mathrm{MJ} / \text { litre and } \mathrm{CO}_{2} \\
\text { emissions 2.641 kgCO2/litre (DEFRA, 2010) }\end{array}$ \\
\hline Electricity & 151 & $\begin{array}{l}\text { UK grid rolling average } \mathrm{CO}_{2} \text { emissions 542 } \\
\text { g/kWh including transmission and distribution } \\
\text { losses (DEFRA, 2010) }\end{array}$ \\
\hline Hydrogen & 91.7 & $\begin{array}{l}\text { Produced from steam reformed natural gas } \\
\text { according to assumptions in (Offer, 2010) }\end{array}$ \\
\hline
\end{tabular}


This is a pre-print version of: Howey, D.A., et al., Comparative measurements of the energy consumption of 51 electric, hybrid and internal combustion engine vehicles, Transportation Research D (2011), DOI 10.1016/j.trd.2011.04.001

Table 4: Summary of $\mathrm{CO} 2$ emissions results

\begin{tabular}{ll} 
Vehicle type & $\begin{array}{l}\text { gCO2/km emissions } \\
\text { (average) }\end{array}$ \\
\hline EV & $76-151(93)$ \\
\hline HEV & $52-157(85)$ \\
\hline ICE & $67-168(118)$ \\
\hline HFEV & 110 \\
\hline
\end{tabular}

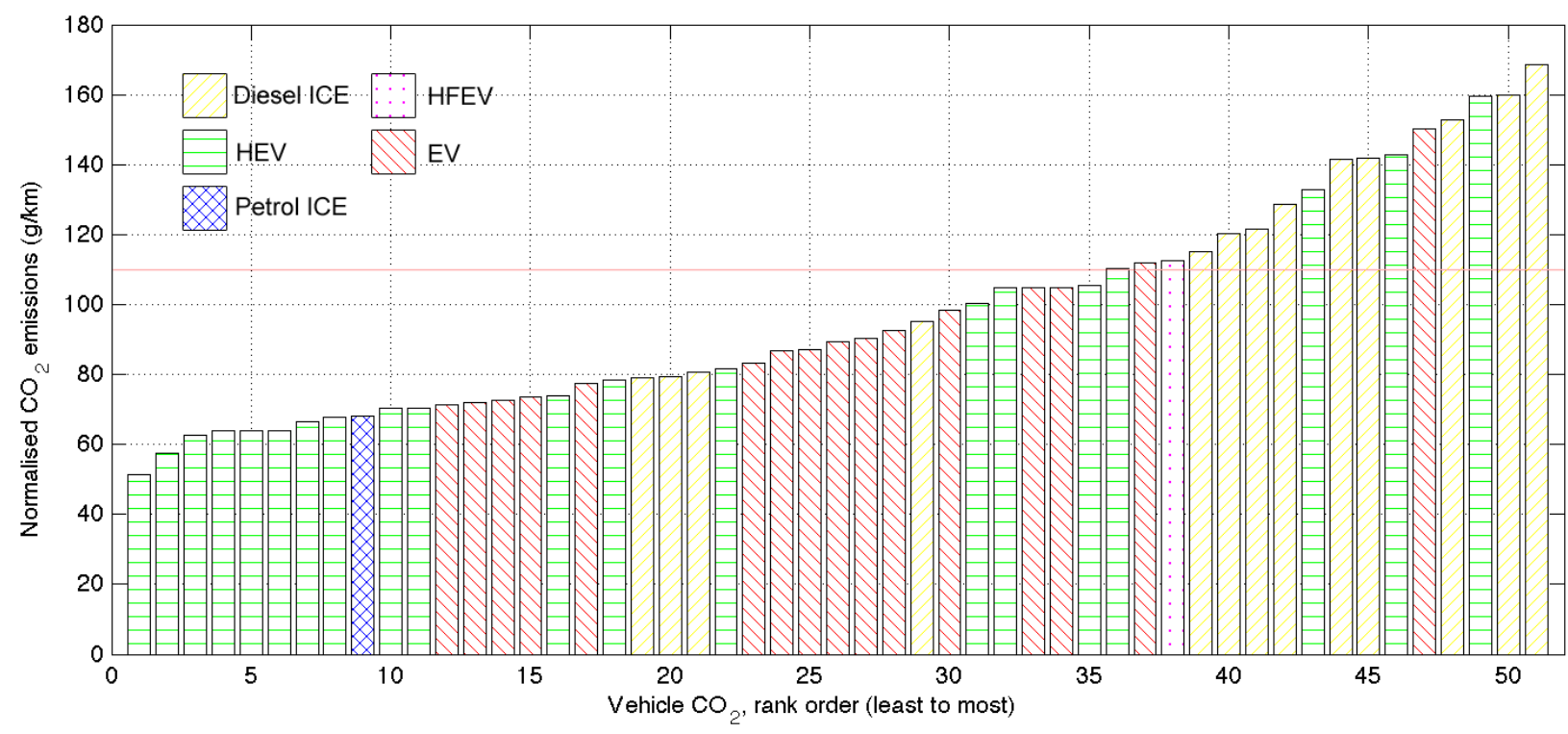

Figure 4: $\mathrm{CO}_{2}$ results with horizontal line showing emissions of $110 \mathrm{gCO}_{2} / \mathrm{km}$

\section{Discussion and conclusions}

In terms of energy consumption the main finding is that on average the different vehicles fall into three distinct categories. The electric vehicles - which consisted of 7 sports car size, 3 regular, 3 small, 2 LCVs and 1 MPV - used the least amount of energy. The hybrid vehicles - consisting of 18 regular size and 2 sports cars - made up the mid-range. The ICE vehicles - consisting of 7 small size, $1 \mathrm{LCV}$ and 6 regular vehicles - were the highest consuming group. There is some overlap between the categories, more so between HEVs and ICE vehicles, as might be expected given the range of possible drivers and vehicle sizes and types. In general though this result demonstrates the greater average tank-to-wheel efficiency of EVs and HEVs in comparison to ICE vehicles. Indeed, the latter typically have maximum efficiencies of $25-35 \%$ (Knight, 2010), whereas the efficiencies of electric powertrains can in the best case exceed $90 \%$.

The $\mathrm{CO}_{2}$ emissions results are subject to more speculative assumptions and are therefore more challenging to interpret primarily due to the difficulty in comparing unlike energy sources. The fairest comparison method would consider well-to-wheel emissions, i.e. with all upstream sources accounted for, and could also account for the full product lifecycle, although the usage phase dominates (Samaras, 2008). Such analysis was outside the scope of the current research. It was therefore chosen to use the tailpipe $\mathrm{CO}_{2}$ emissions factors for petrol and diesel vehicles (including ICEs and HEVs) and the UK 'grid average' factor for electricity. Under these assumptions, HEVs performed best, with half of the competing vehicles emitting less than $70 \mathrm{gCO}_{2} / \mathrm{km}$.

There is a stark contrast between these $\mathrm{CO}_{2}$ figures and the 'official' figures published for the vehicles. The BLFCC event entry requirement for ICE vehicles was a maximum tailpipe limit of 110 $\mathrm{gCO}_{2} / \mathrm{km}$ as measured by the New European Driving Cycle (NEDC) which is used to test cars for pre-sales regulatory type approval in the European Union (shown by a horizontal line on Figure 4). As these results demonstrate, 9 out of 14 ICE vehicles which claimed to emit less than 110 $\mathrm{gCO}_{2} / \mathrm{km}$ exceeded this threshold, some by as much as $50 \%$. This confirms concerns about the appropriateness of the NEDC in assessing real-world emission levels (Joumard, 2000). 
This is a pre-print version of: Howey, D.A., et al., Comparative measurements of the energy consumption of 51 electric, hybrid and internal combustion engine vehicles, Transportation Research D (2011), DOI 10.1016/j.trd.2011.04.001

The emissions results for EVs are obviously sensitive to the assumptions made about the electricity grid. It could be argued that a marginal emissions factor (MEF) would provide a more accurate reflection of the $\mathrm{CO}_{2}$ emissions. Because marginal electricity supply in the UK is currently met largely by gas and coal-fired power stations, the MEF is higher than the AEF, around 690 $\mathrm{gCO}_{2} / \mathrm{kWh}$ (Hawkes, 2010). Using this factor would mean that the $\mathrm{CO}_{2}$ emissions of the EVs would have to be increased by $27 \%$. The grid emissions factors will likely improve in the future as the UK government seeks to improve $\mathrm{CO} 2$ emissions under the UK Climate Change Act.

\section{References}

AC Propulsion website, http://www.acpropulsion.com/faqs.html, accessed 03/02/2011

BRUSA NLG5 Battery Charger User's Manual, from www.brusa.biz, accessed 03/02/2011

DEFRA, 2010 Guidelines to Defra / DECC's GHG Conversion Factors for Company Reporting, produced by AEA for the Department of Energy and Climate Change (DECC) and the Department for Environment, Food and Rural Affairs (Defra), UK, Version 1.2.1 FINAL Updated: 06/10/2010, available from http://www.defra.gov.uk/environment/business/reporting/conversion-factors.htm, accessed 03/02/2011

Hawkes, A. D., Estimating marginal $\mathrm{CO}_{2}$ emissions rates for national electricity systems. Energy Policy 38(10):5977-5987, 2010.

Joumard, R. et al., Influence of driving cycles on unit emissions from passenger cars. Atmospheric Environment, 2000. 34: p. 4621-4628.

Knight, B., Better mileage now. Scientific American 302(2), 50-55, 2010.

Offer, GJ, Howey, DA, Contestabile, M, Clague, R and Brandon, NP, Comparative analysis of battery electric, hydrogen fuel cell and hybrid vehicles in a future sustainable road transport system. Energy Policy 38(1):24-29, 2010

Samaras, C. and Meisterling, K., Life cycle assessment of greenhouse gas emissions from plug-in hybrid vehicles: implications for policy. Environmental science and technology, 2008. 42(9):31703176. 